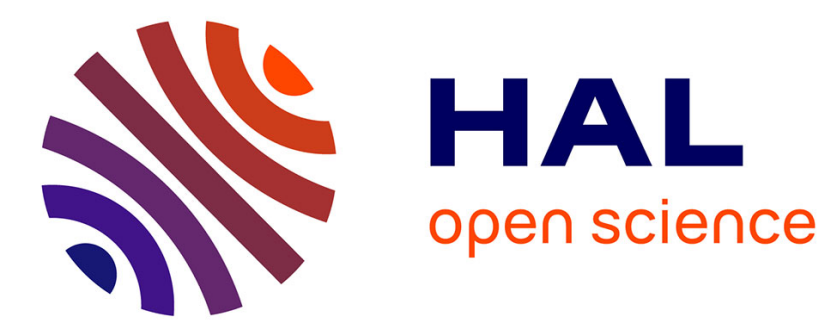

\title{
Modeling the role variability in the MAP process model
}

Rebecca Deneckere, Irina Rychkova, Selmin Nurcan

\section{To cite this version:}

Rebecca Deneckere, Irina Rychkova, Selmin Nurcan. Modeling the role variability in the MAP process model. RCIS, 2011, Guadeloupe, France. pp.180-188. hal-00703641

\section{HAL Id: hal-00703641 \\ https://hal.science/hal-00703641}

Submitted on 4 Jun 2012

HAL is a multi-disciplinary open access archive for the deposit and dissemination of scientific research documents, whether they are published or not. The documents may come from teaching and research institutions in France or abroad, or from public or private research centers.
L'archive ouverte pluridisciplinaire HAL, est destinée au dépôt et à la diffusion de documents scientifiques de niveau recherche, publiés ou non, émanant des établissements d'enseignement et de recherche français ou étrangers, des laboratoires publics ou privés. 


\title{
Modeling the role variability in the MAP process model
}

\author{
Rébecca Deneckère ${ }^{+}$, Irina Rychkova ${ }^{+}$, Selmin Nurcan $^{+,}$* \\ $(+)$ Centre de Recherche en Informatique \\ Université Paris I - Panthéon Sorbonne \\ 90, rue de Tolbiac, 75013, Paris \\ (*) Sorbonne Graduate Business School \\ 21, rue Broca, 75005, Paris \\ \{Rebecca.Deneckere, Irina.Rychkova, Selmin.Nurcan\}@univ-paris1.fr
}

\begin{abstract}
Business process modeling is a valuable technique helping organizations to specify their processes, to analyze their structure and to improve their performance. Conventional process modeling techniques are proven to be inefficient while dealing with non-repetitive, knowledge-intensive processes such as Case Management processes. In this work we use the MAP notation to model a Mortgage Approval Process as defined in Banking. To increase the navigability and practical value of map models, we extend the MAP notation with the concepts of Roles, Relations between roles, and Role Configuration Rules.
\end{abstract}

\section{Keywords: Role ; Process model MAP}

\section{INTRODUCTION}

In the modern economy, companies are more and more interested in expanding their businesses and exploring new markets. Proliferation of Information and Communication Technologies (ICT) fosters collaboration and makes people across the globe work together as they are sitting in one office. Working cultures, local policies and regulations, however, remain specific to a country or a region forcing the companies to customize their processes for each particular case and to take into account where and under which conditions the process is executed) [1].

Business process modeling is a valuable technique helping organizations to specify their processes, to analyze their structure and to improve their performance. Conventional techniques for business process modeling are imperative - they encourage the early specification of the control flow [2][3][4]. Using these techniques, specification of numerous options and variations in a process model related to its context of execution becomes tedious if at all possible [5][6][7][8].

Similar problem statements have been identified and studied in the area of process engineering.

For more than ten years process engineering remains a key issue for the information system (IS) communities [9]. For instance, [10] [11] [12] [13] show that an improved development process leads to improved productivity of the software systems industry and improves systems quality.
Similarly to a business process, IS development process was traditionally organized into sequences of activities (e.g., "analysis," "design," "coding," "testing") [14] [15], with a rigid control flow. Later on, these activity sequences were replaced by values and practices [16] [17]. However, [18] highlights that, in practice, IS engineers are faced with countless methodical choices: they can choose to execute one activity completely or partially, to combine aspects of two or more different activities, or to ignore an activity. Thus, decisions made through the IS development process should reflect the situation at hand and help an IS engineer to specify and enact a unique process adapted to this situation.

In response to this problem, several methodologies supporting intentions have been developed [19] [20] [21]. Intention-oriented process modeling focuses on what the process is intended to achieve (i.e. what is the reason behind the process execution), instead of how it is going to achieve. [22]. Nevertheless, many of these methodologies do not employ the concept of intention/goal as an integral part of their process model. These process models focus on how the process is performed and externalize what the process is intended to accomplish - the intention. In MAP process models, [21], in contrast, the intentional level is used to guide engineers through IS processes by dynamic choices of the executable service sequences. Each time when an intention is realized, the model suggests an executable service (or several alternative services) that can be invoked on the next step. The resulting IS development process is adaptive and flexible as it is constructed dynamically following the situation.

In this paper we use the MAP methodology to model a Mortgage Approval Process as defined in Banking. Providing a flexible mechanism for flexible and customizable process specification, original MAP notation, nevertheless, remains restrictive: it does not allow us to specify roles for this process.

The concept of Role is a key concept in process modeling. Roles are present in nearly all process models - they help the modeler to structure the process model, by grouping the responsibilities and answering the question "who does what?". IS designer, developer, stakeholder, decision-maker, client, 
clerk - are all examples of roles. According to [27] the role is the definition of an organizational intention shared by a collection of users, all of whom having the same privileges and obligations to a set of work processes in an organization. The role is also the main concept for the representation of cooperative processes. In other words, the role is the basic block of the organization perspective [47], which reflects information about the organizational structure and actors to which the business process is intended. Roles can be represented and used differently in process models depending on the notation.

The original MAP meta-model presented in [21] does not include the concept of Role. However, roles implicitly participate in decision-making in all the levels of an organizational process expressed by a map. For example, it can be a specific role responsible for making a choice between several alternatives in the map. The notion of role will then be useful to explicitly define who can take the navigation decisions. Roles can also be present in the description of an executable service (e.g. some activities may be performed by specific roles and only them). Therefore, in order to improve guidance on maps, it is important to include the concept of role into the MAP metamodel.

In this work we extend the MAP notation with the concepts of Roles, Relations between roles, and Role Configuration Rules. These modeling concepts were introduced as a part of DeCo (Declarative Configurable Process Specification) approach in [1]. This mechanism allows us to anticipate abundant variations of context as, even within the same bank, different agencies may have different stuffing and thus, different distribution of responsibilities between employees. As a result, different actors may be required/available to execute the Mortgage Approval Process. We will demonstrate how these variations can be incorporated within the same map.

The reminder of this paper has the following structure. In Section 2 we discuss the related works and identify the advantages of MAP applied to modeling case management processes. We also explain the limitations of the existing MAP notation and provide the rationale for its extension. In Section 3 we present an example of the Mortgage Approval Process and explain the MAP meta-model on this example. In Section 4 we extend the MAP notation with the mechanism to explicit Role variability modeling. In Section 5 we present our conclusions and discuss our future work.

\section{RELATED WORK}

\section{A. Process flexibility}

Business process modeling is a valuable technique helping organizations to specify their business processes, analyze their structure and improve their performance. Conventional techniques for business process modeling are imperative - they encourage the early specification of the control flow. However, for certain forms of business processes the control flow cannot be identified at design time.

One of the examples is a Case Management Process [25]. The case management process can be characterized as follows: it (i) has a descriptive nature, (ii) varies largely depending on its execution context, (iii) involves a lot of, often implicit, decision making resulted from communication/ negotiation among human actors, (iv) is based on the available/emerging case-related knowledge [26]. For such processes, early specification of the control flow is not only challenging but also unnecessary and even harmful.

As advocated in [27] an unstructured (i.e. without predefined control flow) process cannot be represented in terms of flow of tasks or activities or operations... The model proposed in [27] allows to represent it as a 'black box' associated to a set of resources that it uses and produces and a set of participating roles. The key concept of such kind of unstructured processes is the information and knowledge sharing in the work group (i.e. among actors playing roles).

Another paradigm to deal with non-prescriptive or non imperative processes is provided by conversation models. The latter are based on the speech act theory and on the principle that each sentence expressed by someone represents an intention, a commitment [28]. For instance, the Action model [29] defines a structure to represent the conversation relationship between two participants, customer and performer.

The type of process models addressed in [30], [31], [32] is based on the decision-oriented paradigm according to which the successive transformations of the product are considered as consequences of decisions. The underlying paradigm is that a process model does not have only to specify the linking of activities or product states but also the intention behind the execution of activities and their ordering at the run time. Decision-oriented models guide the decision making process that shapes the business and thus help reasoning about the rationale of decisions [33]. This paradigm seems to be the particularly appropriate for representing processes requiring flexibility.

This paradigm does not require modeling the process control flow in advance and allows alternative strategies to be considered.

\section{B. Variability}

In [34][35] the concept of configurable process has been presented and the modeling formalism to deal with process configurability at multiple perspectives is defined. Namely the authors present the Configurable Integrated EPC (C-iEPC) modeling notation that extends the well-known Event Process Chain (EPC) notation and addresses the process configurability along the control-flow, data, and resource perspectives. According to this approach, "Given a configurable process model, analysts are able to define a configuration of this model by assigning values to its variation points based on a set of requirements. Once a configuration is defined, the model can be individualized automatically."

In [26] the method for Declarative Configurable process specifications (DeCo) is presented. This method defines an extension to BPMN [36] graphical notation and identifies three types of relations between roles: synonym, alternative and specialization. 


\section{Roles and Actors}

The concept of Role is closely related to the concept of Actor in modeling methodologies. Various definitions of Actors and Roles can be found in literature. The most common definition states that an Actor specifies a Role played by a user or any other system that interacts with the subject [37]. In I* [19], actors are considered as "active entities that carry out actions to achieve goals by exercising their know-how and could be composed of Agents, Roles and Positions, each of which is an actor in a more specialized sense". OPF [38] gives another definition of an actor (a producer) which is "a core abstract method component that models someone or something that performs work units" (produces work products or provides services).

Several attempts have been made to introduce the concept of Role in the MAP notation [39][23]. In [39], the MAP metamodel has been extended with the concept of Indicator. Indicators are used to help decision-making in the navigation through a process map. A typology of indicators was defined based on well-known project characteristics (for instance the cost, the duration, the formality degree, and so on). This indicator typology includes a particular indicator, which represents the Expert role. This indicator is used to define which roles are linked to each executable services of a map. However, this information, even if it helps the guidance through a map, doesn't give the user enough information about the variability inherent to the role concept. For instance, it cannot be used to know if a specific expert role is related to other expert roles in the project.

In [23] the concept of Role has been added to the MAP meta-model in order to support the "operationalization" of MAP process models. Namely, this concept provides an explicit relation between an intentional process perspective captured by MAP process model and its organizational perspectives described by a business process. Enhancing the MAP notation using the role concept also allowed us to explicitly link navigation guidelines associated to a map with the roles executing them. Namely, for the intention selection and the strategy selection guidelines, the role taking the navigation decisions can be specified. For the intention achievement guidelines, the role executing the corresponding section in the map can be specified. The third capability added to the MAP notation thanks to the role was the possibility to deal with non-structured processes as suggested previously in [27]. While improving the traceability between different process perspectives, the extended MAP process model presented in [23] provides little guidance for process users and does not enable process customizations.

The purpose of this work is to enhance the concept of Role in MAP and to provide the mechanisms for (i) expressing role variability and (ii) role configuration. These mechanisms will improve the guidance on maps taking into account all the role relationships present in the project.

\section{APPlying MAP to CASE MANAGEMENT PROCESS MODELING}

\section{A. Example: The Mortgage Approval Process}

In this paper we consider an example of processing a mortgage claim as defined by different financial institutions in the USA. The information provided below results from our study of multiple information sources (e.g. http://www. homebuyinginstitute.com/, http://www.mortgage-resourcecenter.com/, http://homebuyereducation.bankofamerica.com/, http://www.homeloancenter.com/ etc.). It represents a compilation of guidelines, recommendations, and descriptions of the Mortgage Approval Process, provided by different loan consulting firms, financial advisors, and banks, available on the web.

A mortgage is a loan for buying a house. On the USA market, there exist various mortgages that will be appropriate for special situations such as bad credit loans, first time homebuyer, etc. The terms and length of the mortgages are negotiable and can be adapted for the applicant's situation.

The mortgage approval process can be divided into the following steps:
1. Pre-qualification
2. Formal application
3. Document review
4. Pre-approval
5. Property appraisal
6. Final Approval
7. Closing

The goal of the pre-qualification step is to determine the potential mortgage amount that the applicant is eligible for. The purpose of the formal application is to provide the lender with a package of documents characterizing in details the current financial situation (assets) of the applicant as well as his/her employment and credit history. Document review follows the formal application and may include the preapproval step. The pre-approval letter issued as a result of a pre-approval indicates that a thorough analysis of the applicant's credit, income, and assets has been completed and that the applicant is pre-approved by a lender for a specific loan amount. Being optional, this letter, however, may represent a valuable negotiation instrument for an applicant while searching for a property. When the applicant selects the property, the potential mortgage lender initiates the Property appraisal. The result of the appraisal defines the amount of the mortgage and a corresponding down payment that has to be paid by the applicant. The lender makes "approve", "not approve", or "approve with conditions" final decisions based on the document review and the appraisal results. If the loan is approved, a commitment letter is issued for the applicant, and a closing date is set up. Closing (also called settlement) is a final step. During the mortgage closing, the mortgage lenders will purchase the house and hold the title, as the applicant makes payments to them.

Pre-qualification and Pre-approval are compulsory steps; Pre-approval and Property appraisal can be considered as parts 
of a Document review and serve as a basis for the Final approval.

Below, we illustrate how this process can be modeled using the MAP meta-model.

\section{B. The MAP meta-model}

Goal modeling is an effective way for identifying requirements of software systems by focusing on understanding the intentions of the involved stakeholders [40] [41] and the process model MAP is an example of goal model that has been conceived to meet this challenge. A map expression provides a synthetic view of the variability of a process in a relatively easy to understand way. Variations are revealed in two ways, by the gradual movement down the different levels of a top map, and by the alternative strategies/paths available at a given map level [42]. The intentional MAP meta-model has been introduced in the IS engineering domain [21] and validated in several fields: requirement engineering [43], method engineering [44], enterprise knowledge development [45] and process modeling [21].

The map corresponding to the mortgage appraisal process is presented in Fig. 1.

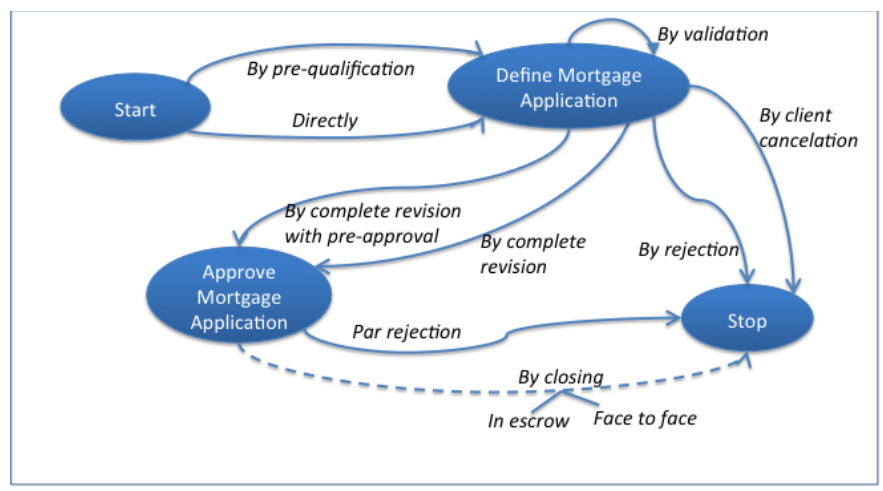

(a)

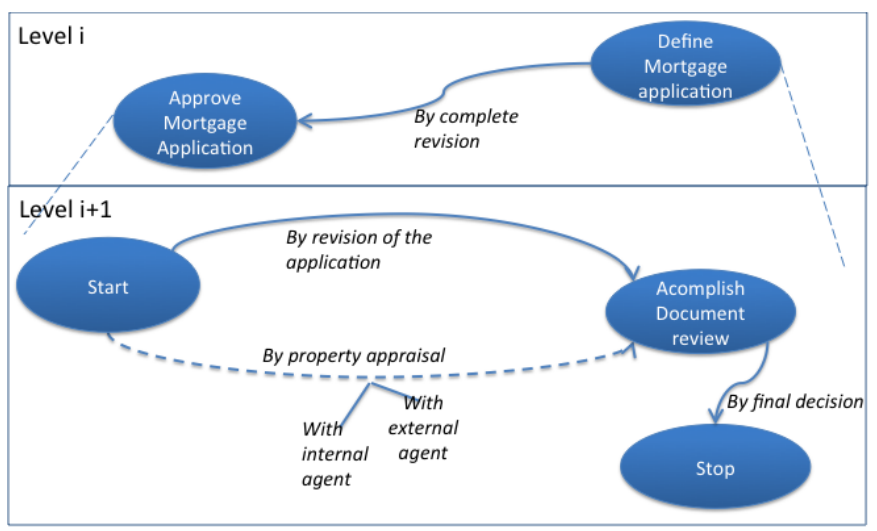

(b)

Figure 1. High level map of the Mortgage Approval Process and Refinement map of the section A of this map

A map is a diagram composed of nodes and edges. Nodes are intentions to realize and edges are strategies to reach these intentions. An edge enters a node if its associated strategy can be used to achieve the target intention (the given node). Since there can be multiple edges entering a node, a map is able to represent multiple ways to achieve an intention.

Fig.1 (a) represents a High-level map of the mortgage approval process defined in the previous section. There are two intensions specified on this level: Define Mortgage Application and Approve Mortgage Application. The former intention is realized when the Formal application is completed and validated (steps 1 and/or 2 of the example); the latter is realized when Final Approval decision is made (step 6 of the example). The final intention (Stop) corresponds to the process termination and can be realized either by Closing the mortgage (in case of a positive approval decision) (step 7) or by rejection of the mortgage claim otherwise.

Fig.2 shows the MAP model using the UML formalism. The key element of a map is a section. A section represents a triplet: a source intention, a target intention, and a strategy linking these source and target intentions. The section corresponds to a process of achieving the target intention from a specific situation following a particular strategy. In Fig.1 (a) the triplet $<$ Define Mortgage application, By complete revision with pre-approval, Approve mortgage application $>$ represents a section that can be interpreted as follows: when the application has been completed and validated, the process can continue to its final approval following the complete revision with a pre-approval intermediate step.

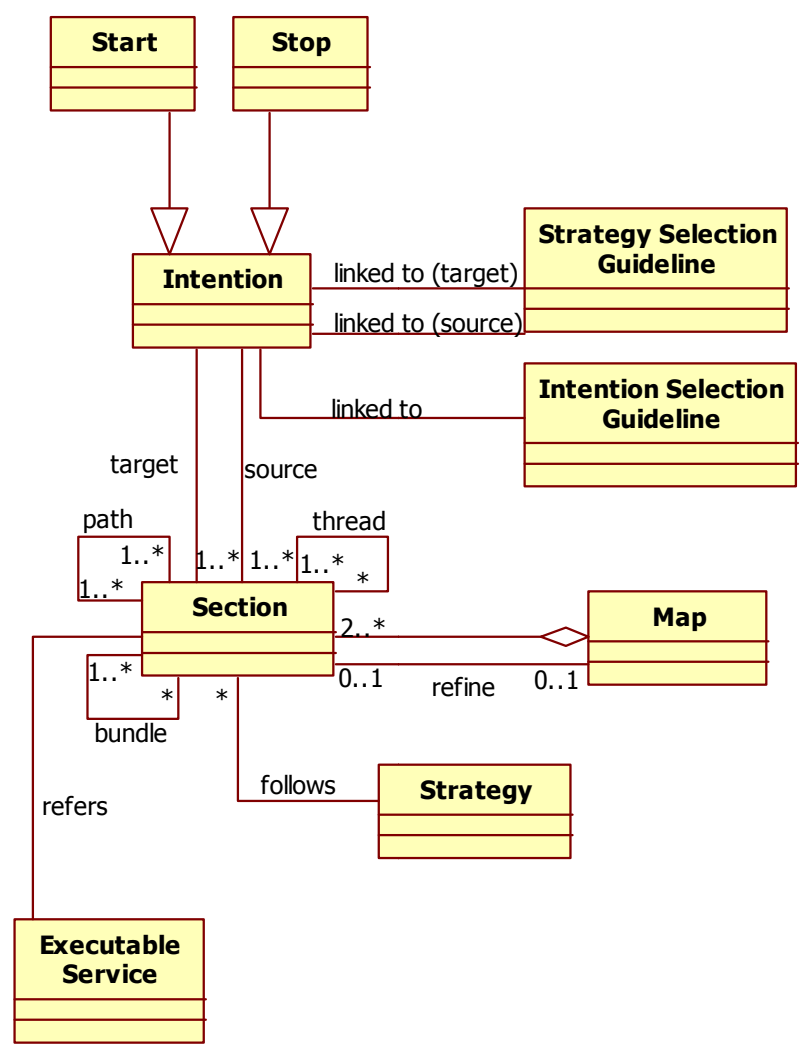

Figure 2. MAP meta-model 
Three kinds of relationships are defined for sections: thread, path and bundle.

A thread relationship represents the possibility to achieve a target intention from the source intention following several different paths (defined by a different strategy). Each of these paths can be seen as a section in the map. Multiple strategies leading to an intension describe multiple ways to realize this intension. On the High-level map shown in Fig.1 (a), the Approve Mortgage Application intention can be realized either by complete document revision, which include Document review (step 3) and Property Appraisal (step 5) or by complete revision with Pre-approval (steps 3-4-5).

A path relationship represents the precedence (or the order) between sections. We say that one section succeeds (precedes) another if and only if the source (target) intention of the former is the target (source) intention of the latter. There is absolutely no path predefined as the engineer constructs his own path following the situation at hand. Given the thread and the path relationships, an intention can be achieved by several combinations of sections. In our example, the mortgage lender can navigate through the map presented in Fig.1 (a) in order to approve a mortgage. Several paths are possible, e.g. the application can be submitted directly or following the prequalification procedure first; approval can be granted without the pre-approval step or with the latter, etc.

A bundle relationship shows the possibility for several sections having the same source and target intentions to be mutually exclusive. (Mutual exclusion is depicted by dashed lines in a map). In Fig. 1 (a) the strategy "By closing" linking the Approve Mortgage Application intention to the terminal intention Stop represents a bundle relationship. It combines two sections that are mutually exclusive: either the closing is done in escrow or face-to-face.

A section in a map may be refined with another map using the refinement relationship. Refinement is an abstraction mechanism by which a complex assembly of sections at level $i+1$ is viewed as a unique section at level $i$. This relationship introduces levels in the process representation as each map may be represented as a hierarchy of maps. Fig.1 (b) represents the refinement of a section of the high level map illustrated in Fig.1 (a) and provides more details on Final Approval process of a mortgage application.

When a section cannot be refined any further, an Executable Service that fulfills the intention may operationalize it. It implies the transformation of the product under development with the execution of a service (which can be a guideline, a workflow, an algorithm, a business process model, etc.).

A map specifies one 'Intention Selection Guideline' (ISG) per each intention $I_{i}$, except for 'Stop' intention. Given an intention $I_{i}$, an ISG identifies the set of intentions $\left\{I_{j}\right\}$ that can be achieved in the next step and proposes arguments to select one of them. There is also one 'Strategy Selection Guideline' (SSG) per intentions pair $\left\langle I_{i}, I_{j}\right\rangle$. Given two Intentions $I_{i}, I_{j}$ and a set of possible strategies $\mathrm{S}_{\mathrm{ij} 1}, \mathrm{~S}_{\mathrm{ij} 2}, . . \mathrm{S}_{\mathrm{ijn}}$ applicable to $I_{j}$, the associated SSG guides the selection of a $S_{i j k}$. We can say that
ISGs and SSGs describe the know-how of a domain in socalled decision process chunks [23].

\section{EXTENDING MAP FOR ROLE AND ROLE VARIABILITY MODELING}

Enabling multiple strategic choices, the MAP specification does not provide enough information for realization of these choices. One of the recurrent problems is the role assignment.

As specified in DeCo [1], synonyms, alternatives, optional/obligatory process elements and hierarchies of elements defined by generalization/specialization relations provide a mechanism for modeling process variability. The configuration rules, on the other hand, support the configuration of variants based on the situation.

In this work we apply these mechanisms to model variability of roles in maps. In our example, the roles associated with the Mortgage Approval Process can vary not only from country to country and from one bank to another following theirs internal policies, but also from one agency to another within one bank (e.g. based on the size of this agency). Whereas some sections of an abstract mortgage process illustrated in Fig 1(a) can be assigned to abstract actors (e.g. Mortgage lender), concrete role assignments for the refined Mortgage Approval Process (Fig. 1(b)) may depend on the financial institution: small banks have only several (2-4) roles associated with the process, whereas in big agencies the application processing and decision making is more likely to be assigned to a number of different roles with different responsibilities. As our study shows, the same responsibility can also be performed by several roles or delegated from one role to another according to some internal rules.

As a result, different actors may be required/available to execute the Mortgage Approval Process. Thus, to provide the efficient guidance for both administration and personnel of a bank, an explicit specification of roles, relations between them (e.g. hierarchy, alternatives or possible replacements, and synonyms) is required.

\section{A. Enhanced MAP concepts}

Role variability is important in the real life process descriptions: in the organizations the same responsibilities are often associated to multiple roles, at the same time, some role names can have double meaning depending on the project or process. Thus, the process gets overloaded with exceptions and becomes extremely complex providing little support and guidance. To get more practical value, the explicit specification of roles, their relations and rules of role configuration/ assignment is required.

Figure 3 represents an extended meta-model of MAP and includes the following concepts: Role, Relations between roles, and Role Configuration Rule. These concepts enable a mechanism for modeling role variability in MAP process models. Variability of roles in business process models is a mechanism to address the organizational complexity. It was discussed in [35]. 


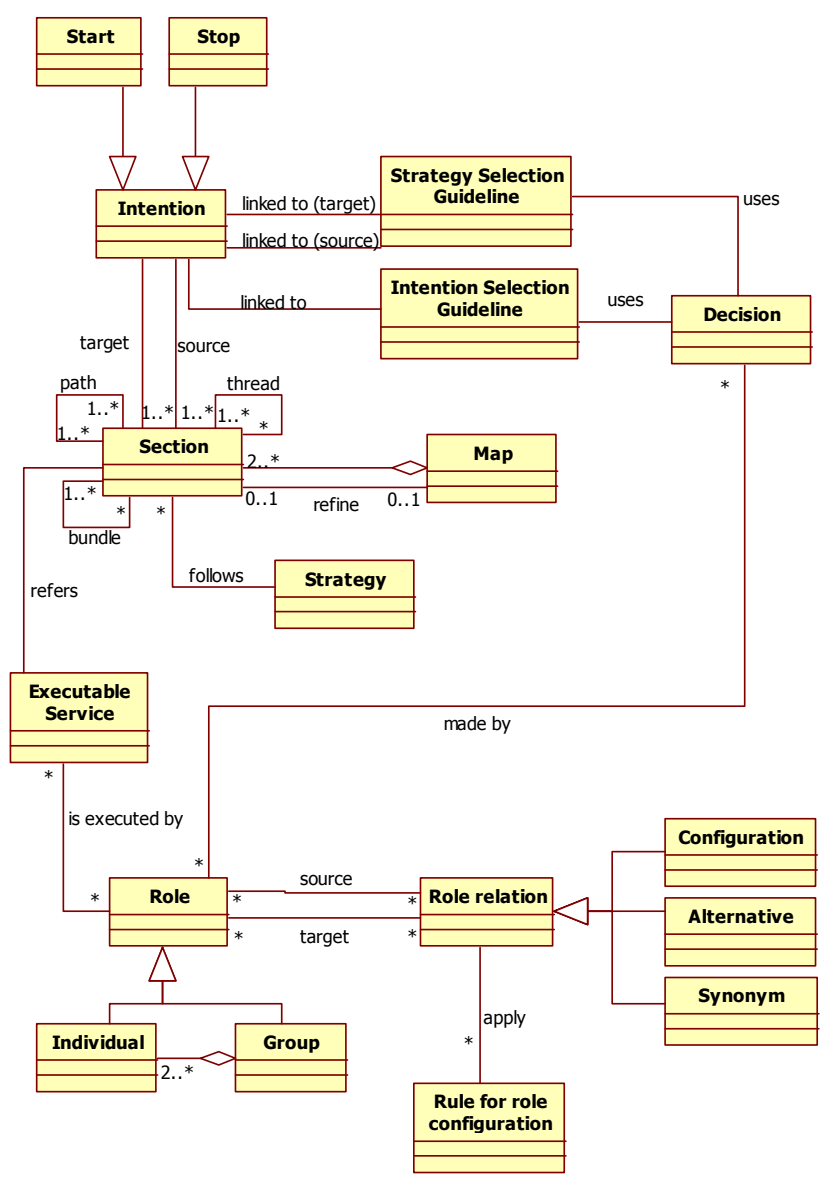

Figure 3. Enhanced MAP meta-model

A role is the definition of an organizational intention shared by a number of actors [46]. Role can be identified with a set of responsibilities and can be fulfilled by one or several actors in the organization. Loan consultant, Loan officer, and Appraisal agent - are examples of roles.

In the enhanced MAP meta-model, the concept of role is specialized into individual role and group role. For example, Loan Consultant is an individual role whereas a Loan Processor is a group role. A group role contains several individual roles.

As in [26] [1], we define three types of relations between roles: Synonym, Alternative and Configuration.

Role configuration expresses possible instantiation of a generic role into configured roles. For instance, the Mortgage Lender may be configured into several other roles, as the Loan Consultant, the Loan processor, the Closing Agent and so on.

Within a configuration, different roles can be related via synonym or alternative relations.

Synonym relation expresses the fact that a specific role can be found in different organizations/processes under different names while still encapsulating the same set of responsibilities (i.e. this role has "synonyms"). For example, in the Mortgage Approval Process, the Loan Consultant role is a synonym to the Loan Broker role. Thus, during the process instantiation, both roles can be assigned to the same actor.

Alternative relation expresses the fact that, under specific conditions, the responsibilities associated with one role can be fulfilled by another role (or delegated to it). For example, if the local agency does not have its own Appraisal agent, an External Appraisal agent can be recruited to perform the property appraisal task. Along those lines, the role of the Loan Processor, that performs an application revision and decision making, can be fulfilled by a Loan Broker (for the smaller agencies).

We associate the executable service supporting a map section to one or several roles. This captures the knowledge about which tasks can be taken by which role and offers a better guidance of the map execution. The executable service (i.e. a business process chunk [23], a method chunk [42]...) encapsulates a process knowledge specified in the organizational layer (by answering what, who, when, where and how questions).

\section{B. Modeling the Role hierarchy for Mortgage Approval Process}

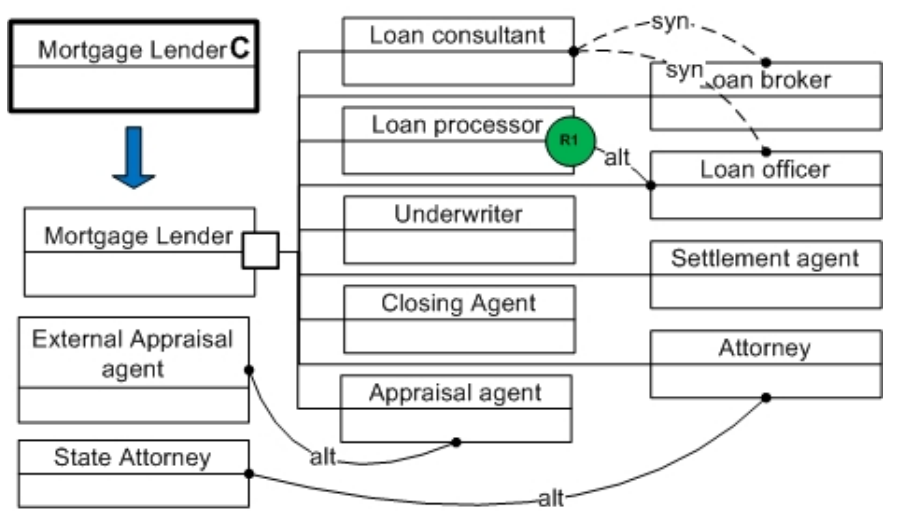

Figure 4. Role hierarchy and relations between roles in Mortgage Approval Process

Figure 4 illustrates the hierarchy of Roles defined in Mortgage Approval Process. The roles are modeled as rectangles (following the UML notation) with the name in the upper compartment.

A rectangle with thick outline and the " $\mathrm{C}$ " in the right corner is a "compact" notation that refers to a role that can be further configured in the process model based on the situation or context. We envisage integrating the Role element into the MAP notation using this compact representation. For convenience, the configuration details can be shown on a separate diagram as represented in Fig.4.

In our example, the abstract role Mortgage lender combines a set of complementary and possibly overlapping responsibilitie. These responsibilities can be fulfilled by a single actor or shared by a group of actors, giving a rise to more specific roles: Loan Consultant, Loan Processor, Underwriter, etc.

In the diagram representing the details of role configuration, we define another two types of relations 
between roles: Synonym relation, depicted by a dashed line with a tag "syn" and Alternative relation, depicted by a solid line with a tag "alt". These relations reflect the policies of organization and are used to explicitly describe "who does what" based on the concrete context.

Namely, the synonym relation refers to the fact that in the context of a given process, two roles have absolutely the same responsibilities. Thus, they can be defined interchangeably (for different organizations for example). In our example, Loan Broker and Loan Officer roles are synonyms of the Loan Consultant role as within the mortgage approval process they fulfill the same responsibilities.

The alternative relation refers to the situations when the responsibilities of one role can be delegated to another role, otherwise not having those responsibilities. In our example in Fig.4, Loan Processor role has an alternative - the Loan officer role. This alternative is bounded by a condition R1 (depicted with a shaded circle) meaning that whenever the number of agents in the local agency is less then 6 persons, the responsibilities in the Mortgage approval process normally fulfilled by a Loan Processor can (will) be fulfilled by a Loan Officer.

Along those lines, External Appraisal Agent and State Attorney are alternative roles for the bank Appraisal agent and Attorney respectively. These alternatives can be activated whenever their corresponding roles inside the bank are unavailable.

We emphasize here that all the considered relations can be defined for a given process only, e.g. whereas for one process two roles can be considered as synonyms, for another process this will not necessarily be the case as the sets of responsibilities fulfilled by the same role within different processes might be different.

We specify configuration rules for the role diagram. These rules define the conditions when the synonym or alternative relation between roles can be activated; they can be expressed in a form of a predicate evaluating to True if condition is satisfied at a given context of False otherwise. In our example depicted in Fig. 4 the Rule R1 describes a condition for activating alternative relation: it states that the number of agency employees should be less than 6 in order to activate the alternative relation between the Loan Processor and Loan Officer roles. Otherwise, in a bigger agency, the documents revision should not be delegated to a Loan Officer.

Fig.5 illustrates other examples of rules that can be used to configure the roles: the availability of a given role in the real environment, geographical location of an agency - these and many other factors can affect the configuration of the process model, in particular imposing the role and actors configuration.

$$
\text { R1 \# agents }<6
$$

\section{isAvailable (InternalAppraisalAgent $)=$ true agencyLocation $=$ North Carolina}

Figure 5. Role configuration rule examples
Configuration rules can be defined on the level of a company, its country division, and/or its local branch or agency.

The extended map with the role specifications is illustrated in Fig. 6.

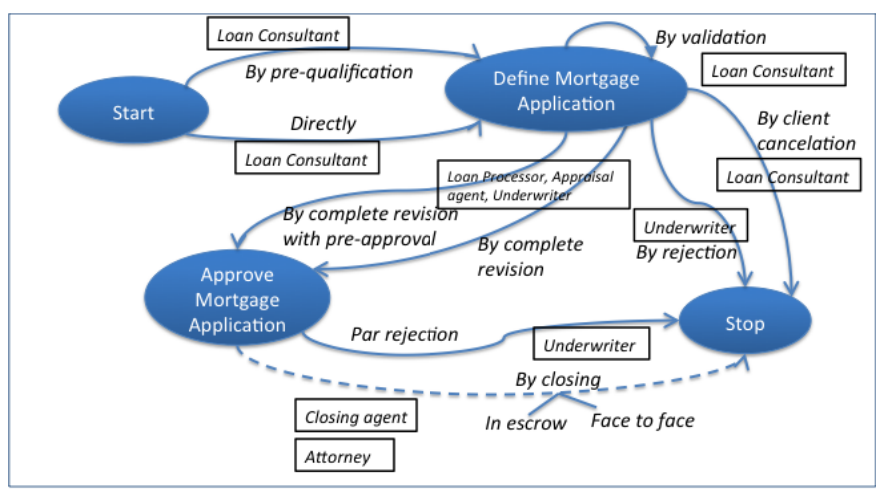

(a)

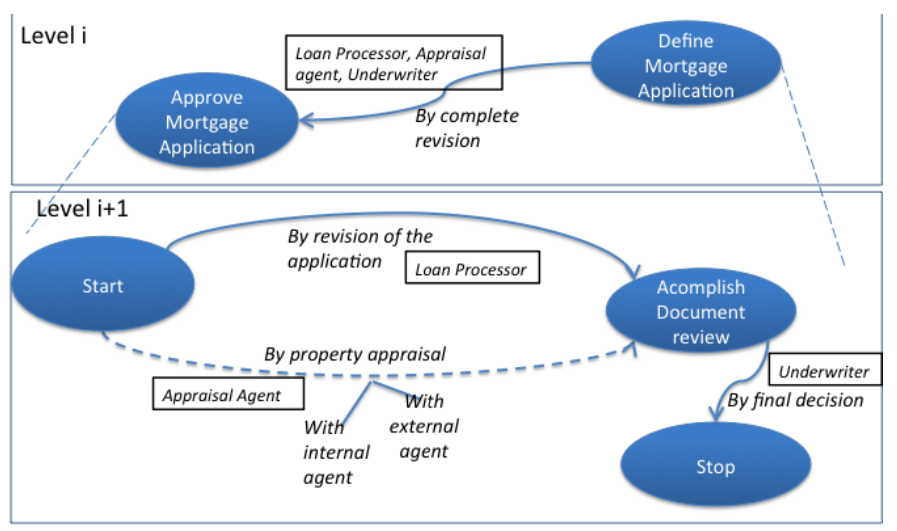

(b)

Figure 6. Mortgage approval process enhanced maps

The upper part of the figure depicts the high level view on the Mortgage Approval Process. The section A represents the process of our interest - the Mortgage approval as executed by a Bank. This section is assigned to the abstract role of Mortgage Lender.

The bottom part of Fig. 6 represents the refinement of this section and can be interpreted as follows:

The mortgage application can be made either by following a pre-qualification process or by directly making an appointment in a bank (we call it "a personal contact"). The Loan Consultant is a role responsible for guiding the client through both of these processes. After the formal application is completed, the document review process is initiated by the mortgage lender; this process consists of several steps and can be accomplished following different paths. The pre-approval of the mortgage is assigned to a single role (the Loan Processor). The final approval should be carried out by the Loan Processor and should be accompanied by the property appraisal process carried out by the Appraisal agent. There are three roles assigned for the closing process. Grateful 


\section{CONCLUSION AND FUTURE WORK}

This paper proposes a mechanism to model roles and role variability in the intentional meta-model MAP. Namely, we extended the MAP notation with the concepts of Roles, Relations between roles, and introduced the Role Configuration Rules (formalization of these concepts will be addressed in our future publications).

The proposed mechanism enables a better guidance and navigation on maps as each process step can be defined for specific roles only. The number of proposed alternatives to navigate through the map is then reduced to the steps compatibles with the user role.

We illustrated our modeling process on the example of the Mortgage Approval process as defined in the USA banks (the simplified specification has been considered). The Mortgage approval process is an example of Case Management process. As shown in [26], modeling this process using traditional imperative modeling style can be difficult if at all possible. In this paper we demonstrated the advantages of intentional modeling using MAP enriched with role modeling mechanism. The first advantage is that the main user (the mortgage lender in our example) has a perfect view of the stakeholders involved into processes. The second advantage is that the resulting model allows us to anticipate variations of context (e.g. different bank agencies having different distribution of responsibilities between employees) while managing the model complexity.

Proposed notation for modeling role variability is not limited for MAP; as proposed in DeCo [1], it can be used to extend another process modeling notations such as BPMN [36].

In future, we plan to extend the notation proposed in this work by adding cardinality constraints.

\section{REFERENCES}

[1] I. Rychkova, S. Nurcan, "Towards Adaptability and Control for Knowledge-Intensive Business Processes: Declarative Configurable Process Specifications". Proceedings of the 44th Annual Hawaii International Conference on System Sciences, Kauai, Hawaii, USA, 4-7 January 2011.

[2] S. Jarzabek, T.W.Ling, "Model-based support for business reengineering", Information and Software Technology, 38(5), 1996, pp. 355-374.

[3] H.-E. Eriksson, M. Penker, "Business modeling with UML - Business patterns at work", J. Wiley, New-York, 2000.

[4] D.A. Marca, C.L. McGowan, "IDEF0/SADT: Business Process and Enterprise Modeling”, Eclectic Solutions, Inc, San Diego, 1993.

[5] J. Lee, "Extending the Potts and Bruns Model for Recording Design Rationale”, ICSE'93, Austin, Texas, 1991.

[6] A. I. Antón, , W. M. McCracken, , C. Potts, "Goal Decomposition and Scenario Analysis in Business Process Reengineering", CAiSE'94, Utrecht, The Netherlands, 1994.

[7] G.A. Rummler, A. P. Brache, "Improving Performance", JosseyBass Publishers, Indianapolis, 1995.

[8] E.S.K. Yu, J. Mylopoulos, "Using Goals, Rules and Methods to Support Reasoning in Business Process Reengineering",
Intelligent Systems in Accounting, Finance and Management, Vol. 5, 1996.

[9] C. Rolland, "A Comprehensive View of Process Engineering", CAISE'98, Springer-Verlag, 1998

[10] M. Dowson, "Software Process Themes and Issues", IEEE Conf. on the Software Process, 1993

[11] P. Armenise, S. Bandinelli, C. Ghezzi, A. Morzenti, "A survey and assessment of software process representation formalisms", Int. Journal of Software Engineering and Knowledge Engineering, Vol. 3, No. 3, 1993

[12] M. Jarke, K. Pohl, C. Rolland, J.R. Schmitt; "Experienced-Based Method Evaluation and Improvement: A Process Modeling Approach", Int. IFIP WG8. 1 Conf. in CRIS series: Method and associated Tools for the Information Systems Life Cycle, North Holland, 1994

[13] O.Jaufman, A. Dold, T. Haeberlein, C. Schlumpberger, M. Stupperich, "Requirements for flexible software development processes within large and long taking projects", QUATIC'04, Porto, Portugal, October 2004.

[14] W. W. Royce, "Managing the development of large software systems: concepts and techniques". In Proceedings of Wescon, 1970

[15] B. Boehm, "A Spiral model of software development and enhancement". IEEE Computer 21, 5, 61-72, 1988

[16] K. Beck, "Extreme programming eXplained: embrace change", 2nd ed. The XP Series. Addison Wesley, Boston, MA, USA, 2005

[17] P. Abrahamsson, O. Salo, J. Ronkainen, and J. Warsta, "Agile software development methods: Review and analysis", VTT Publications, Espoo, 2002

[18] P. Ralph, Y. Wand, "A Teleological Process Theory of Software Development", in Proceedings of JAIS Theory Development Workshop. Sprouts: Working Papers on Information Systems, 8, 23, 2008

[19] A. van Lamsweerde, "Reasoning About Alternative Requirements Options", Conceptual Modeling: Foundations and Applications, 2009, p. 380-397

[20] D. Amyot, G. Mussbacher, "URN: Towards a New Standard for the Visual Description of Requirements", In proceeding of 3rd Int. WS on Telecommunications and beyond: the broader applicability of SDL and MSC, 2002.

[21] C. Rolland, N. Prakash, A. Benjamen, "A Multi-Model View of Process Modeling". Requirements Engineering. Volume 4, Number 4. Springer-Verlag London Ltd, 1999

[22] J.L.G. Dietz, "Basic Notions Regarding Business Processes and Supporting Information Systems", Proceedings of BPMDS'04, Latvia, Riga, 2004, pp.160-168

[23] S. Nurcan, "Business Process Modeling for developing Process Oriented IT Systems". The "Business Process Management Tools and Technologies" track of IRMA'04, New Orleans, USA, May 23-26, 2004.

[24] S. Nurcan, M.-H. Edme. "Intention Driven Modeling for Flexible Workflow Applications". Special issue of the Software Process: Improvement and Practice Journal on "Business Process Management, Development and Support", 10:4, 2005.

[25] Keith D. Swenson, "Mastering the Unpredictable. How adaptive case management will revolutionize the way the knowledge workers get things done". Meghan-Kiffer Press, 2010.

[26] I. Rychkova, S. Nurcan. "The Old Therapy for the New Problem: Declarative Configurable Process Specifications for the Adaptive Case Management Support", BPMS2'10, Hoboken, New Jersey, USA, September 2010. 
[27] S. Nurcan, "Main concepts for cooperative work place analysis", Proceedings of the XV. IFIP World Computer Congress Telecooperation, Vienna, Austria, 1998, pp. 21-36.

[28] J.R. Searle, "A taxonomy of illocutionary acts", K. Gunderson (Ed.), Language, mind and knowledge, Minneapolis, University of Minnesota Press, 1975, pp 334-369.

[29] R. Medina-Mora, T. Winograd, R. Flores, F. Flores, "The Action Workflow Approach to Workflow Management Technology", CSCW'92, Toronto, Canada, 1992.

[30] B. Dellen, F. Maurer, G. Pews, "Knowledge Based Techniques to Increase the Flexibility of Workflow Management. Data and Knowledge Engineering", 23(3), North Holland, 1997

[31] G. Faustmann, "Enforcement vs. Freedom of Action- An Integrated Approach to Flexible Workflow Enactment", Workshop on Adaptive Workflow Systems. Conference on CSCW, Seattle, USA, 1998

[32] S. Nurcan, A. Etien, A. Kaabi, I. Zoukar, C. Rolland, "A Strategy Driven Business Process Modeling Approach", Special issue of the Business Process Management Journal on "Goaloriented business process modeling", Emerald, 11:6., 2005

[33] A. McLean, T. Moran, R.M. Young, "Design Rationale: The argument behind the artifact". CHI'93 Conference Proceedings, ACM, 1989, pp 247-256.

[34] M. Rosemann, W. M. P. van der Aalst, "A Configurable Reference ModelingLanguage". Information Systems, 2007

[35] M. La Rosa, M. Dumas, A.H.M. ter Hofstede, J. Mendling, "Configurable multi-perspective business process models", Preprint submitted to Information Systems. Available at QUT Digital Repository: http://eprints.qut.edu.au/, 2009

[36] Object Management Group, Business Process Model and Notation (BPMN) FTF Beta 1 for Version 2.0 OMG, 2009

[37] "OMG Unified Modeling Language (OMG UML), Superstructure, V2.1.2", http://www.omg.org/spec/UML/2.1.2/Superstructure/PDF. November 2007, pp. 586-588.

[38] B. Henderson-Sellers, "Process meta-modeling and process construction: examples using the OPF". Ann. Software Engineering 14(1-4), 2002, pp.341-362.
[39] R. Deneckere, E. Kornyshova, "Process Line Configuration - an Indicator-based Guidance of the Intentional Model MAP”, EMMSAD'10, Hammamet, Tunisie, 2010.

[40] A. An'on, C. Potts, "The use of goals to surface requirements for evolving systems". In Proceedings of the 20th International Conference on Software Engineering, 1998.

[41] E. S. K. Yu, J. Mylopoulos, "Understanding "why" in software process modeling, analysis, and design”, ICSE'94, 1994, pages 159168

[42] C. Rolland, "Capturing system intentionality with maps", in the book Conceptual Modeling in Information Systems Engineering, Krogstie, John; Opdahl, Andreas Lothe; Brinkkemper, Sjaak (Eds.), 2007

[43] N. Prakash, C. Rolland, "Systems Design for requirements expressed as a map", Proc. of the conference IRMA 06, Washington DC, 2006.

[44] E. Kornyshova, R. Deneckère, C. Salinesi, "Method Chunks Selection by Multicriteria Techniques: an Extension of the Assemblybased Approach", ME 07, Geneva, Switzerland, 2007.

[45] J. Barrios, S. Nurcan, "Model Driven Architectures for Enterprise Information Systems", 16th Conference on Advanced Information Systems Engineering, (CAISE'04), Springer Verlag (pub) , Riga, Lettonie, 2004.

[46] S.Nurcan, C.Rolland, "A meta-model for goal driven cooperative work processes". First Workshop on the Many Facts of process Engineering, September 22-23, Gammarth , Tunisie, 1997, pp. 245-260.

[47] Daoudi, F. and Nurcan S. (2007) A benchmarking framework for methods to design flexible business processes. Special issue of the Software Process: Improvement and Practice Journal on "Business Process Management", January 2007. 